\title{
Empirical research on the relationship between Informatization and Regional Economic Development of Qinghai Province
}

\author{
WEI Li, LI YI ${ }^{1}$, LIU Ya fei ${ }^{1}$, DING Sheng $\mathrm{xi}^{1}$ \\ ${ }^{1}$ Finance and Economy College, Qinghai University, Xi'ning, 810016, China
}

\begin{abstract}
This paper according to the characteristics of Qinghai Province System, constructs the evaluation index of informatization and regional economic development level, and the relationship between informatization and regional economic development in Qinghai Province is analyzed and calculated emphatically based on gray correlation method. The results show that the influence of different indicators on the regional economic development of Qinghai Province is different. Finally, the author puts forward some suggestions on the coordinated development of informatization construction and regional economy in Qinghai Province.
\end{abstract}

\section{Introduction}

Qinghai Province is located in the Qinghai-Tibet Plateau, the economic development is relatively backward. In recent years, China is also paying particular attention to informatization construction, so many domestic experts and scholars have carried out in-depth explore and research[1-5]. We can see that domestic scholars are very concerned about the impact of informatization on economic growth, affirming the important role of informatization on economic and social development. However, in the context of the western development, the empirical research on informatization and economic development in Qinghai Province is extremely lacking. Therefore, this paper takes the relationship between informatization and economic development in Qinghai Province as the research object, selects the evaluation index related to informatization and regional economic development, and uses the gray relational dynamic analysis method to carry on the empirical analysis, and it is not only the reality of economic and social development needs, but also an innovation of this article.

\section{The Establishment of Index System}

\subsection{The Establishment of Indicator System of Informatization Level}

In late July 2001, the Ministry of Information Industry in the national information of the indicators of the meeting officially announced a detailed national information technology indicators program, the program consists of 20 indicators. In 2006, the International Statistical Information Center of the National Bureau of Statistics designed the second set of information technology to evaluate the overall index [6]. Based on the actual situation in Qinghai Province, this paper forms the evaluation index system with three first-level indicators and 10 secondary indicators (Table 1 ).

Table 1 Evaluation Index System of Informatization Level in Qinghai Province

\begin{tabular}{|c|c|c|c|}
\hline First index & Second index & Unit & $\begin{array}{c}\text { Variable } \\
\text { identifier }\end{array}$ \\
\hline \multirow{4}{*}{$\begin{array}{l}\text { Informatization } \\
\text { infrastructure }\end{array}$} & The number of telephones per one hundred people & [set] & $\mathrm{X} 1$ \\
\hline & The number of televisions per hundred households & [set] & $\mathrm{X} 2$ \\
\hline & The number of computers per hundred households & [set] & $\mathrm{X} 3$ \\
\hline & The number of internet users per hundred households & [household] & $\mathrm{X} 4$ \\
\hline \multirow{3}{*}{$\begin{array}{c}\text { Informatization } \\
\text { development status }\end{array}$} & The tel-communications total quantity per capita & {$[\mathrm{RMB}]$} & $\mathrm{X} 5$ \\
\hline & The number of scientific and technical personnel per ten thousand people & [person] & X6 \\
\hline & The number of scientific research institutions & [ea] & $\mathrm{X} 7$ \\
\hline
\end{tabular}




\begin{tabular}{cccc}
\hline $\begin{array}{c}\text { Informatization } \\
\text { development } \\
\text { potential }\end{array}$ & The proportion of tertiary industry employment & {$[\%]$} & X8 \\
& The number of college students per ten thousand people & [person] & X9 \\
The R\&D expenditure per capita & {$[$ RMB] } & X10 \\
\hline
\end{tabular}

\subsection{The Establishment of Regional Economic Development Index System}

This paper constructs the economic development index system of Qinghai Province through five indicators (Table 2).

Table 2 Evaluation Index System of Regional Economic Development Level in Qinghai Province

\begin{tabular}{ccc}
\hline Index & Unit & Variable identifier \\
\hline GDP & {$[$ hundred million RMB] } & Y1 \\
Investment in Social Fixed Assets & {$[$ hundred million RMB] } & Y2 \\
Total retail sales of consumer goods & {$[$ hundred million RMB] } & Y3 \\
Fiscal budgetary revenue & {$[$ hundred million RMB] } & Y4 \\
Tertiary industry growth rate & {$[\%]$} & Y5 \\
\hline
\end{tabular}

\section{Gray Correlation Dynamic Analysis of Informatization and Regional Economic Development in Qinghai Province}

\subsection{Analysis principles and methods}

Gray correlation analysis, is to quantify the research object and the object to be identified and the factor values of their influencing factors separately. And according to the similarity or dissimilarity of the development trend among the factors, that is, "gray relational degree", as an analysis method to measure the degree of correlation between the factors [7]. This paper chooses the gray correlation method as an important research tool.

The specific calculation methods and steps are as follows:

(1) Identify the reference series that reflect the system behavior characteristics and the comparison sequence that affects the system behavior

The sequence of data that reflect the system behavior characteristics, called a reference sequence. The sequence of data that affects the system behavior is called the comparison sequence.

(2) Dimensionless method of the reference sequence and the comparison sequence

The formula is:

$$
X_{i}(k)=x_{i}(k) / x_{1}(k)
$$

Where $x_{i}(k)$ is the raw data and $X_{i}(k)$ is the raw data initialization result

(3) Calculate the difference sequence of the reference sequence and the comparison sequence. The formula is:

$$
\Delta_{i}(k)=\left|Y_{i}(k)-X_{i}(k)\right|
$$

(4) Find two range in sequence $\Delta_{i}(k)$

$$
M=\max \left|Y_{i}(k)-X_{i}(k)\right|
$$

$$
m=\left|Y_{i}(k)-X_{i}(k)\right|
$$

(5) Calculate the correlation coefficient. The formula is:

$$
L_{i}(k)=m+\delta M / \Delta_{i(k)}+\delta M
$$

Among them, $\delta$ is the resolution coefficient, the resolution coefficient $\delta$ in the range of $0-1$, generally take $\delta=0.5$.

(6) Calculate the degree of correlation

The degree of correlation is calculated as follows:

$$
r_{i}=\sum L_{i}(k) / n
$$

\subsection{Gray correlation dynamic analysis on the regional economic development of Qinghai Province by each informatization indicator}

Since the western development in 1999, the development of informatization and regional economy in Qinghai Province has been not smooth sailing, and experienced a tortuous development process. This paper divides this process into three stages. Respectively, calculated and contrast analyzed the relationship between informatization and regional economic development, and tries to find out the changing trends and law.

First, 10 informatization level indicators in Qinghai Province from 1999 to 2005 were used as the comparison sequence, $X_{i}=\left\{X_{i}(t), t=1,2, \ldots, 17\right\}(i=1,2, \ldots, 10)$ Five economic development levels were selected as the reference sequence, $Y_{i}=\left\{Y_{i}(t), t=1,2, \ldots, 17\right\}(i=1,2, \ldots, 5)$ Create a gray correlation sequence. According to the calculation method of the above gray correlation degree and combined with EXCEL software can draw the corresponding gray correlation matrix, see Table 3. 
Table 3 Gray Relational Matrix of the Relationship between Informatization and Regional Economic Development in Qinghai Province from 1999 to 2005

\begin{tabular}{cccccccccccc}
\hline & $\mathbf{X 1}$ & $\mathbf{X 2}$ & $\mathbf{X 3}$ & $\mathbf{X 4}$ & $\mathbf{X 5}$ & $\mathbf{X 6}$ & $\mathbf{X 7}$ & $\mathbf{X 8}$ & $\mathbf{X 9}$ & $\mathbf{X 1 0}$ \\
\hline Y1 & 0.9753 & 0.9922 & 0.6164 & 0.6135 & 0.9779 & 0.9874 & 0.9928 & 0.9903 & 0.9754 & 0.9745 \\
Y2 & 0.9818 & 0.9853 & 0.6171 & 0.6142 & 0.9822 & 0.9806 & 0.9859 & 0.9835 & 0.9819 & 0.9810 \\
Y3 & 0.9722 & 0.9956 & 0.6166 & 0.6137 & 0.9751 & 0.9908 & 0.9963 & 0.9938 & 0.9723 & 0.9714 \\
Y4 & 0.9788 & 0.9884 & 0.6164 & 0.6135 & 0.9805 & 0.9836 & 0.9890 & 0.9866 & 0.9789 & 0.9780 \\
Y5 & 0.9690 & 0.9968 & 0.6183 & 0.6154 & 0.9708 & 0.9920 & 0.9957 & 0.9950 & 0.9714 & 0.9706 \\
\hline $\begin{array}{c}\text { Correlation } \\
\text { degree }\end{array}$ & 4.8770 & 4.9582 & 3.0848 & 3.0702 & 4.8865 & 4.9342 & 4.9598 & 4.9491 & 4.8799 & 4.8757 \\
\hline
\end{tabular}

It can be seen that the correlation degree sort of informatization and regional economic development in Qinghai Province at this stage is:

$$
\mathrm{X}_{7}>\mathrm{X}_{2}>\mathrm{X}_{8}>\mathrm{X}_{6}>\mathrm{X}_{5}>\mathrm{X}_{9}>\mathrm{X}_{1}>\mathrm{X}_{10}>\mathrm{X}_{3}>\mathrm{X}_{4}
$$

It can be seen, Qinghai Province in 1999-2005, the number of scientific research institutions has the most significant impact on the regional economic development. Followed by the number of televisions per hundred households and the proportion of the tertiary industry employment population. The next are the number of scientific and technical personnel per ten thousand people, the tel-communications total quantity per capita, the number of college students per ten thousand people, the number of telephones per one hundred people, the R\&D expenditure per capita, the number of computers per hundred households, the number of internet users per hundred households.

Similarly, the relationship between informatization and regional economic development in Qinghai Province in 2006-2010 was analyzed for gray correlation analysis. The results are shown in Table 4.

Table 4 Gray Relational Matrix of the Relationship between Informatization and Regional Economic Development in Qinghai Province from 2006 to 2010

\begin{tabular}{ccccccccccccc}
\hline & $\mathbf{X 1}$ & $\mathbf{X 2}$ & $\mathbf{X 3}$ & $\mathbf{X 4}$ & $\mathbf{X 5}$ & $\mathbf{X 6}$ & $\mathbf{X 7}$ & $\mathbf{X 8}$ & $\mathbf{X 9}$ & $\mathbf{X 1 0}$ \\
\hline Y1 & 0.7638 & 0.6288 & 0.6868 & 0.9079 & 0.7147 & 0.6377 & 0.6231 & 0.6445 & 0.8088 & 0.6735 \\
$\mathbf{Y 2}$ & 0.7869 & 0.6796 & 0.7310 & 0.8684 & 0.7828 & 0.6884 & 0.6816 & 0.6938 & 0.7913 & 0.8088 \\
Y3 & 0.8285 & 0.6663 & 0.7355 & 0.9129 & 0.6688 & 0.6771 & 0.6626 & 0.6847 & 0.8513 & 0.7040 \\
Y4 & 0.7119 & 0.6215 & 0.6634 & 0.7980 & 0.8512 & 0.6286 & 0.6190 & 0.6331 & 0.7419 & 0.7478 \\
Y5 & 0.8291 & 0.9450 & 0.9080 & 0.7478 & 0.6367 & 0.9247 & 0.8893 & 0.9417 & 0.7886 & 0.7166 \\
\hline $\begin{array}{c}\text { Correlation } \\
\text { degree }\end{array}$ & 3.9203 & 3.5412 & 3.7248 & 4.2351 & 3.6543 & 3.5565 & 3.4756 & 3.5978 & 3.9820 & 3.6508 \\
\hline
\end{tabular}

During this time, the gray correlation degree sort is: $\mathrm{X}_{4}>\mathrm{X}_{9}>\mathrm{X}_{1}>\mathrm{X}_{3}>\mathrm{X}_{5}>\mathrm{X}_{10}>\mathrm{X}_{8}>\mathrm{X}_{6}>\mathrm{X}_{2}>\mathrm{X}_{7}$

The influencing factors in the top three are the number of internet users per hundred households, the number of college students per ten thousand people and the number of telephones per one hundred people. Followed by the number of computers per hundred households, the tel-communications total quantity per capita and the R\&D expenditure per capita. The last four are the proportion of the tertiary industry employment population, the number of scientific and technical personnel per ten thousand people, the number of televisions per hundred households and the number of scientific research institutions.

At last, the gray relational matrix of the relationship between informatization and regional economic development in Qinghai Province from 2011 to 2015 is obtained from the above method.

Table 5 Gray Relational Matrix of the Relationship between Informatization and Regional Economic Development in Qinghai Province from 2011 to 2015

\begin{tabular}{ccccccccccccc}
\hline & $\mathbf{X 1}$ & $\mathbf{X 2}$ & $\mathbf{X 3}$ & $\mathbf{X 4}$ & $\mathbf{X 5}$ & $\mathbf{X 6}$ & $\mathbf{X 7}$ & $\mathbf{X 8}$ & $\mathbf{X 9}$ & $\mathbf{X 1 0}$ \\
\hline Y1 & 0.7343 & 0.6337 & 0.9282 & 0.8690 & 0.7413 & 0.6391 & 0.7144 & 0.7074 & 0.7139 & 0.6695 \\
$\mathbf{Y 2}$ & 0.6213 & 0.5859 & 0.6641 & 0.7120 & 0.7760 & 0.5874 & 0.6128 & 0.6118 & 0.6128 & 0.5990 \\
Y3 & 0.6874 & 0.6094 & 0.8160 & 0.8608 & 0.7976 & 0.6140 & 0.6704 & 0.6644 & 0.6670 & 0.6386 \\
Y4 & 0.6957 & 0.6151 & 0.8585 & 0.8252 & 0.7381 & 0.6169 & 0.6802 & 0.6790 & 0.6874 & 0.6408 \\
Y5 & 0.8715 & 0.9019 & 0.7336 & 0.7251 & 0.6965 & 0.8954 & 0.8889 & 0.8530 & 0.8382 & 0.9009 \\
\hline $\begin{array}{c}\text { Correlation } \\
\text { degree }\end{array}$ & 3.6102 & 3.3459 & 4.0003 & 3.9921 & 3.7495 & 3.3529 & 3.5668 & 3.5156 & 3.5192 & 3.4488 \\
\hline
\end{tabular}


During this period, the gray correlation degree sort is:

$$
\mathrm{X}_{3}>\mathrm{X}_{4}>\mathrm{X}_{5}>\mathrm{X}_{1}>\mathrm{X}_{7}>\mathrm{X}_{9}>\mathrm{X}_{8}>\mathrm{X}_{10}>\mathrm{X}_{6}>\mathrm{X}_{2}
$$

It can be seen from 2011 to 2015 , the first three factors that have the greatest impact on the regional economy in Qinghai Province are the number of computers per hundred households, the number of internet users per hundred households and the tel-communications total quantity per capita. The following factors are the number of telephones per one hundred people, the number of scientific research institutions and the number of college students per ten thousand people. The last four are the proportion of the tertiary industry employment population, the R\&D expenditure per capita, the number of scientific and technical personnel per ten thousand people and the number of televisions per hundred households.

In order to further compare the changes in the impact of various informatization indicators about regional economic development in the three stages. Compare the first six influencing factors in the gray correlation degree sort of the above three periods, as shown in Table 6.

Table 6 A comparison about the correlation degree sort between informatization and regional economic development in Qinghai Province at three different stages

\begin{tabular}{c|c|c|c|c|c}
\hline Stage correlation degree sort & $\mathbf{1}$ & $\mathbf{2}$ & $\mathbf{3}$ & $\mathbf{4}$ & $\mathbf{5}$ \\
\hline $\mathbf{1 9 9 9 - 2 0 0 5}$ & $\mathrm{X} 7$ & $\mathrm{X} 2$ & $\mathrm{X} 8$ & $\mathrm{X} 6$ & $\mathrm{X} 5$ \\
\hline $\mathbf{2 0 0 6 - 2 0 1 0}$ & $\mathrm{X} 4$ & $\mathrm{X} 9$ & $\mathrm{X} 1$ & $\mathrm{X} 3$ & $\mathrm{X} 5$ \\
\hline $\mathbf{2 0 1 1 - 2 0 1 5}$ & $\mathrm{X} 3$ & $\mathrm{X} 4$ & $\mathrm{X} 5$ & $\mathrm{X} 1$ & $\mathrm{X} 7$ \\
\hline
\end{tabular}

\section{Conclusion}

It can be seen from Table 6 that in the first stage, three indicators that have the greatest impact on regional economic development are the number of televisions per hundred households, the proportion of the tertiary industry employment population and the number of scientific and technical personnel per ten thousand people, which exit the top five in the latter two stages. The number of computers per hundred households and the number of internet users per hundred households are not significant from the first stage to the second stage into the top five. Finally, the last stage ranked the top two. Description in recent years, with the gradual development of the Internet, the effect of Internet economy on the development of regional economy in Qinghai Province is more and more obvious. In addition, the tel-communications total quantity per capita and the number of telephones per one hundred people are also from the fifth and seventh of the first stage to the third and forth of the third stage, indicating that the mobile communication business has gradually developed more and more significant impact on the regional economic development of Qinghai Province.

\section{Countermeasure}

\subsection{Strengthen the construction informatization infrastructure.}

According to the above analysis, it can be seen that the number of computers per hundred households and the number of Internet users per hundred households have the highest correlation with regional economic development. Therefore, the government should use a variety of public networks and a variety of access means to achieve information into various households, increase the construction of informatization infrastructure especially open network services for some remote rural users, popularize the knowledge and skills of information technology, so as to promote the all sectors of society can share the country's educational resources, scientific and technological resources, cultural resources, medical and health resources and public services provided by government[9].

\subsection{Perfect talents cultivation in informatization construction}

From the above analysis, we can see that the number of scientific research institutions and the number of college students per ten thousand also have a high degree of correlation with regional economic development. Therefore, colleges and universities in Qinghai Province should strengthen the education of information technology applications, each enterprises and institutions should also establish their own information technology training system, conduct information technology vocational training activities for the staff, improve the overall level of informatization application of each enterprises and institutions. In addition, Qinghai Province should improve the training mechanism, attract high-tech talent, in order to further narrow the regional differences in information[10].

\subsection{Promote the development of informatization industry}

The development of informatization industry is also the key to the informatization construction in Qinghai Province, for existing enterprises engaged in informatization-related enterprises, Qinghai Province should give technical support and policy encouragement, improve the financial, tax and related industrial policies, regard the informatization industry as an important strategic goal of industrial development, encourage, support and guide the development of informatization industry. In addition, Qinghai Province should encourage some non-informatization companies to understand more informatization and strive to the direction of the 
transformation of informatization technology development, for informatization-related start-up companies, the government can relax the loan and provide some policy support to make them develop.

\subsection{Give full play to the government's guidance and coordination function in informatization construction}

Good environment is an effective way to promote the development of informatization, the government should improve the construction of informatization infrastructure, provide a powerful platform for the promotion and popularization of informatization. On the basis of planning and service, the government should respect the objective law of Qinghai Province and give full play to the function of resource allocation in Qinghai Province. In addition, the government can reform the investment mode, actively introduce the market mechanism, attract foreign capital or private capital to invest informatization project construction, give full play to the role of market mechanism in the informatization construction.

\section{Acknowledgements}

This work was financially supported by the National Social Science Fund Program (15BJY003). Corresponding Author is DING Sheng-xi.

\section{References}

1. Tengli and Wangzheng:The Effect of Informatization on Regional Economy in China $[\mathrm{J}]$. Human Geography, China 2006.

2. Meng yuan: Research on the Development of Regional Economy under Informatization Environment [D]. Anhui University, Anhui 2010.

3. Mei lin: An Empirical Study on the Relationship between Regional Informatization and Regional Economic Development in Shanxi Province [J]. China-Today Forum, China 2013.

4. Li ling and Wang li-ping: An Analysis of the Relationship between Regional Informatization and Regional Economy in Anhui Province[D]. Journal of West Anhui University, China 2006.

5. Report on the Evaluation of China's Informatization Level [D]. http://tjyj.stats.gov.cn/CN/Y2006/V23/I2/3.

6. Liu si-feng: Gray System Theory and Its Application [J]. Science Press, China 2010. 